\title{
Identification of Helicobacter pylori and the evolution of an efficacious childhood vaccine to protect against gastritis and peptic ulcer disease
}

\author{
Thomas G. Blanchard ${ }^{1}$ and Steven J. Czinn ${ }^{1}$
}

Establishment of Helicobacter pylori infection as an etiologic agent of peptic ulcer disease and other gastric pathologies marked a revolution in gastroenterology which spurred an enormous interest in gastric physiology and immunology research. The association was soon also demonstrated in children as well. Application of antimicrobial therapies have proven remarkably efficacious in eradicating H. pylori and curing pediatric patients of duodenal ulcers as well as gastritis, negating a lifetime of ineffective therapy and life-threatening disease. Countries with high $H$. pylori prevalence and where $H$. pylori associated gastric cancer remains a primary cause of death due to cancer however would benefit from childhood vaccination. Studies in rodents and humans utilizing oral vaccination with bacterial exotoxin adjuvants demonstrated potential for limiting $\mathrm{H}$. pylori colonization in the stomach. Almost $25 \mathrm{y}$ of vaccine research recently culminated in a phase III clinical trial of over 4,000 children aged 6-15y old to test an oral vaccine consisting of the H. pylori urease B subunit genetically fused to the $E$. coli heat labile toxin. Vaccination was demonstrated to have an efficacy of over $70 \%$. Vaccination may now serve as an effective strategy to significantly reduce H. pylori associated disease in children throughout the world.

\section{HELICOBACTER PYLORI AND THE ETIOLOGY OF GASTRIC DISEASES}

Helicobacter pylori is a Gram negative bacterium that infects the stomach of greater than half of the Earth's population and is a primary cause of gastric pathologies including peptic ulcer disease, dyspepsia, and gastric cancer (1-5). Prevalence varies widely from 10 to $>70 \%(6,7)$. Infections are primarily but not exclusively acquired in early childhood and spread through fecal-oral and oral-oral transmission. Infection lasts for the life of the host and while most infected individuals remain asymptomatic, $10-20 \%$ develops peptic ulcer disease, $1 \%$ develops gastric adenocarcinoma, and $<1 \%$ will develop mucosa-associated lymphoid tissue lymphoma. The World Health Organization has classified $H$. pylori as a definite class I carcinogen (5). Gastric cancer remains the second leading cause of death due to cancer worldwide and large geographic regions including South America, Eastern Europe, and the Far East these levels range from 20 to 40 per 100,000 (8).
The association between $H$. pylori and gastric diseases was not readily accepted by the medical community. Spiral bacteria had been described in human gastric tissue biopsies by microscopy as early as 1906 and periodically throughout the next $70 \mathrm{y}$ (9-12). There were studies however that failed to identify bacteria in gastric biopsy specimens (13). Additionally, there was a general acceptance in the medical community that bacteria could not survive in the acidic stomach and that such observations might be artifacts or evidence of bacterial contamination. The cause of gastritis and peptic ulcer disease was predominantly attributed to stress and were treated by neutralizing acid and with surgery. The debate was renewed in 1983 when Warren and Marshall published their works documenting the presence of spiral bacteria on the gastric epithelium and predominantly associated with active chronic gastritis (14). Importantly, they were also able to culture the bacteria from fresh clinical biopsies with prolonged microaerobic conditions. The bacteria, which would eventually be called $H$. pylori were termed Campylobacter-like organisms. These two investigators subsequently published a similar study linking the bacteria to peptic ulcers as well (2). The gastroenterology community however, largely continued to dismiss the link until, in separate studies, Barry Marshall and Arthur Morris fulfilled Koch's postulates by ingesting cultures of $H$. pylori and demonstrating an associated gastritis and epigastric pain $(15,16)$. Barry Marshall and Robin Warren would receive the Nobel Prize in Physiology or Medicine in 2005 for their work which fundamentally changed our understanding of gastric disease and its treatments.

\section{PREVALENCE OF H. PYLORI INFECTION AND ASSOCIATED DISEASES IN CHILDREN}

Diseases associated with $H$. pylori infection such as peptic ulcer disease and gastric cancer, and even symptomatic gastritis are manifested predominantly in adults. These diseases create a heavy burden on health care systems world-wide because of the prevalence of $H$. pylori. The US Department of Health and Human Services estimate that in the year 2004, $20 \mathrm{y}$ after the identification of $H$. pylori, direct costs associated with peptic ulcer disease reached $\$ 2.6$ billion in the United States alone 
(17). Indirect costs associated with loss of work productivity were estimated to be an additional $\$ 518$ million. Gastric cancer costs were $\sim \$ 487$ million plus an additional $\$ 1.4$ billion in indirect costs. Although these diseases are primarily observed in adults, a vaccine administered in early childhood would still be the most practical given the early age of $H$. pylori acquisition. It is also important to note that $H$. pylori are often present when children are assessed for abdominal pain or dyspepsia.

The first reports of a potential association between $H$. pylori and gastric health in children were all made in 1986. Three independent teams of physicians investigated biopsies for the presence of Campylobacter pyloridis, or Campylobacter-like organisms as $H$. pylori were termed at the time (18-20). Each study examined small numbers of patients including Czinn et al. who performed a detailed histologic analysis of gastric antral biopsies on five patients (19). Endoscopic evaluation revealed small ulcer, antral nodularity, and histologic gastritis. Histologic evaluation revealed diffuse chronic gastritis including well-formed lymphoid follicles in two patients. Higher magnification revealed the presence of spiral bacteria at the epithelium in all five patients.

These studies were followed by a larger scale prospective study by Drumm et al. in which 67 patients undergoing upper endoscopy and biopsy for gastrointestinal symptoms were examined (21). The study is notable for several reasons. First, there was a high degree of association between $H$. pylori and unexplained histologic gastritis. Eighteen of the 67 patients were diagnosed with gastritis by histologic examination. However, eight of those children had gastritis associated with Crohn's disease, eosinophilic gastroenteritis, or were receiving medication with a known association to increased incidence of gastritis. H. pylori were not detected in any of these cases. H. pylori were detected however in 7 of the 10 remaining patients presenting with histologic gastritis. Second, five of the eight patients with unexplained gastritis and positive for $H$. pylori were diagnosed with duodenal ulcers by endoscopy. Although $H$. pylori could be identified in the antrum but not the duodenum, duodenal ulcers were not detected in any of the other 62 patients. Finally, as noted above, H. pylori were not present in any of the biopsies from patients with histologic gastritis due to an underlying cause. Importantly, $H$. pylori were not detected in any of the 49 patients presenting without any evidence of gross or histologic gastritis. This type of control was lacking from many adult studies at the time and provided strong evidence for $H$. pylori's unique association with gastric disease in children.

\section{ESTABLISHING PRINCIPLES FOR A H. PYLORI VACCINE}

$H$. pylori infection can be treated by established antimicrobial therapies. These therapies can vary but in general consist of combination therapies including two antibiotics and a proton pump inhibitor (3). The most recent consensus recommendation supports quadruple therapy and a course of $14 \mathrm{~d}$ (22). Eradication rates as high as $90 \%$ can be achieved in compliant patients. Unfortunately, as these therapies are taken multiple times per day for a minimum of 7-14 d, patient compliance is often poor. They are also often accompanied by side effects including diarrhea and nausea. In addition, it is not fiscally or practically possible to treat one half of the world's population with antimicrobial agents in an effort to cure peptic ulcer disease or prevent gastric cancer. In the United States, if only 10\% of young people are infected, more than one million pediatric patients would be at risk to receive eradication therapy. The cost is prohibitive and it would also lead to the development of antibiotic resistance in both $H$. pylori and other human pathogens. Therefore, a concerted effort has been made toward vaccine development.

It should be noted that chronic $H$. pylori infection is associated with several significant health benefits, particularly in the West where a steady decline in the prevalence of $H$. pylori has coincided with increased esophageal pathologies. An inverse correlation has been described between $H$. pylori infection and Barrett's esophagus (23-25), Barrett's metaplasia (26), esophageal adenocarcinoma (24), and esophageal eosinophilia (27). A meta-analysis on published studies also suggests that $H$. pylori may provide protection from Inflammatory Bowel Disease (28). More significantly with respect to children, an inverse correlation has been described between $H$. pylori infection and allergic asthma (29-31). The protective function of $H$. pylori against allergic asthma has been confirmed in an experimental mouse model and demonstrated to be due to the overriding effects of $H$. pylori induced Treg cells which are able to suppress immune responses against unrelated antigens $(32,33)$. The decision to apply widespread vaccination against $H$. pylori must be considered against the potential increase in other chronic diseases, but in populations where gastric cancer is more prevalent and associated with high morbidity and mortality vaccination would provide an overall advantage.

The nature of $H$. pylori infection has made development of a vaccine technically challenging. Since $H$. pylori resides at the surface of the gastric epithelium and does not invade the tissue, it is able to avoid many aspects of the host immune response. Although neutrophils can cross the epithelium and form crypt abscesses, host defenses against the motile $H$. pylori are limited to secreted antibodies and antimicrobial peptides. It was generally accepted by immunologists that systemic immunizations were ineffective at generating resistance to mucosal pathogens. Additionally, vaccines targeting mucosal tissues also induce weak immunity. The lack of safe and efficacious adjuvants to strengthen mucosal immunogenicity is largely responsible for the paucity of vaccines against venereal diseases and gastrointestinal infections.

One class of mucosal adjuvants is the bacterial exotoxins such as cholera toxin (CT) and E. coli heat labile toxin (LT). The toxins consist of a pentameric ring of $B$ subunits that bind to GM1 gangliosides present on epithelial cells and an A subunit that has enzymatic activity (34). Upon endocytosis of the toxin, the A subunit activates a $G$ protein which ultimately leads to continuous production of cAMP resulting in the efflux of ions and water. In small doses however, these exotoxins are not only immunogenic but when mixed in solution with an unrelated protein antigen confer potent immunogenicity to 


\section{Review | Blanchard and Czinn}

that protein when applied by mucosal immunization (35-37). This technique had been employed with great success in mice to study host immunity to Sendai virus as a model for human influenza by the laboratory of John Nedrud (37). Steven Czinn, a pediatric gastroenterologist and early investigator of $\mathrm{H}$. pylori pathogenesis collaborated with Nedrud to adopt this immunization strategy to demonstrate oral immunization could be used to generate a host immune response to $H$. pylori (38).

Mice were given four weekly doses of $1 \mathrm{mg} \mathrm{H}$. pylori whole cell lysate antigen in combination with $10 \mu \mathrm{g}$ CT adjuvant by oral gavage. They achieved a fivefold increase in anti- $H$. pylori serum IgA titers and a 16-fold increase in intestinal IgA compared with mice immunized without CT. Significant increases in IgG were also noted. Similar results were achieved when immunizing ferrets with $7 \mathrm{mg} \mathrm{H}$. pylori lysate and $60 \mu \mathrm{g}$ CT doses. Ferrets were selected because their stomachs become naturally colonized by the closely related species $H$. mustelae (39). This was the first demonstration that it was possible to induce significant levels of anti- $H$. pylori mucosal immune responses through the use of oral immunization combined with experimental exotoxin adjuvants.

These studies were performed prior to the development of a mouse model for $H$. pylori infection that could utilize immunocompetent mice. However, the use of the cat isolate H. felis was demonstrated to readily infect mice and to induce histologic gastritis similar to that observed in $H$. pylori infected humans within several weeks of infection (40). The development of this animal model made it possible to test the new oral vaccine protocol using a Helicobacter challenge model. Mice were orally immunized with weekly doses of $H$. felis lysate antigen in combination with CT adjuvant and then challenged 7-10 d after the final immunization (41). Mice were then examined $7 \mathrm{~d}$ following challenge and assessed for immunity. Similar to their prior study, Czinn et al. observed significant increases in serum and mucosal anti-H. felis antibody titers including a fourfold increase in gastric IgA, and an eightfold increase in intestinal IgA. Most importantly, $76 \%$ of immunized and challenged mice were determined to be protected from infection whereas only $22 \%$ of control mice were bacteria free. Similar protection was also observed by Chen et al. employing the same mouse model and closely related immunization protocol (42). These studies, combined with new animal models for $H$. pylori infection, served as the foundation for over two decades of studies by numerous laboratories to better characterize $H$. pylori pathogenesis, identify the immune mechanisms that contribute to protective immunity, and to test multiple variations and new strategies for vaccinating against $H$. pylori (43). Protecting mice from $H$. pylori could be accomplished with many candidate protein antigens, by multiple routes of immunization, and with many alternative adjuvants and delivery mechanisms. These results, however, while highly reproducible among laboratories were not so easily translatable in clinical trials.

\section{LIMITED SUCCESS IN EARLY CLINICAL TRIALS}

The first and perhaps most well-known clinical trial to test a $H$. pylori vaccine for efficacy utilized the strategy developed by Czinn and Nedrud in experimental animal models. Given the practical considerations of performing an infectious challenge, and based on studies in mice and ferrets demonstrating success when applying a Helicobacter vaccine therapeutically (44-46), the investigators screened for $H$. pylori infected adults to receive the therapeutic vaccine (47). Groups of 4-6 subjects testing positive for $\mathrm{H}$. pylori based on the $\left[{ }^{13} \mathrm{C}\right]$ urea breath test and by serology were immunized orally with either 180, 60, or $20 \mathrm{mg}$ recombinant $H$. pylori urease plus $5 \mu \mathrm{g}$ LT. Urease was selected based on its extensive use in many immunization experiments which began with the first demonstration of induced protective immunity using a subunit vaccine instead of bacterial lysate antigen (48). They received four weekly doses and then gastric biopsies were collected 1 and 6 mo after the final immunization to evaluate the host immune response and bacterial load. The results were compared with subjects receiving either LT without antigen, or neither LT or antigen.

The study was disappointing to many as $H$. pylori were not eradicated by any of the tested doses. Additionally, the investigators reported significant patient complaints attributable to the vaccine formulation with $62.5 \%$ of subjects developing diarrhea. It occurred within $12 \mathrm{~h}$ of receiving the first dose and lasted for up to $24 \mathrm{~h}$. These episodes decreased with each successive dose, and occurrence was independent of urease dose. It is notable that a subgroup of 12 subjects was initiated with $10 \mu \mathrm{g}$ doses of LT and half of them experienced diarrhea that was significant enough to interfere with daily activities or lasted more than $1 \mathrm{~d}$, prompting the investigators to switch these subjects to $5 \mu \mathrm{g}$ LT in subsequent doses. The results highlight the problems inherent in utilizing exotoxin adjuvants for mucosal immunization. In follow up studies these investigators tested a range of lower LT doses and alternative mucosal routes of immunization to improve safety but were unable to derive a satisfactory protocol to attempt another clinical vaccine trial $(49,50)$.

These results drew attention away from some of the positive aspects of the study. The investigators evaluated induced immunity through the measurement of antiurease antibody titers as well as enumerating the number of circulating urease specific $B$ cells. They achieved significant increases in urease-specific serum IgA in subjects receiving either 180 or $60 \mathrm{mg}$ urease antigen compared with control subjects, and all doses induced significantly greater numbers of urease specific IgA positive antibody secreting cells. More importantly, a significant reduction in bacterial load was achieved in subjects receiving the $20 \mathrm{mg}$ dose of urease and when all subjects receiving urease were combined. While no sterilizing immunity was achieved, this study demonstrated that oral immunization could be used to positively impact mucosal immunity at the gastric mucosa as demonstrated by the reduced bacterial load. Given the predicted difficulties in immunizing against a mucosal pathogen, such a result could be categorized as encouraging despite the lack of efficacy compared with studies in the mouse model.

Three subsequent clinical trials performed by other investigators however were less encouraging. These included another therapeutic vaccine trial employing the use of killed whole cell 
H. pylori in combination with a nontoxic LT variant containing an amino acid substitution (51), a prophylactic vaccine consisting of attenuated Salmonella strains expressing $H$. pylori proteins (52), and a prophylactic trivalent protein vaccine mixed with alum given intramuscularly (53). Although clearance of bacteria was observed in some subjects, the numbers were not greater than that observed for control subjects. It is difficult to define why these subsequent studies failed to achieve the limited success reported by Michetti et al. (47) but the use of the LT exotoxin seems to provide an advantage over other immunization strategies. The primary obstacle therefore involved gaining the benefit of LT adjuvanticity while eliminating its toxicity.

\section{LARGE SCALE CLINICAL SUCCESS WITH AN ORAL CHILDHOOD VACCINE}

The problems associated with previous clinical trials may now have been overcome. The results of a large scale phase III clinical study on a $H$. pylori subunit vaccine were recently reported and demonstrated to have a vaccine efficacy of $71.8 \%$ (95\% confidence interval 48.2-85.6) by the end of the first year (54). The follow up period postimmunization was performed at $3 \mathrm{y}$ and efficacy had fallen to $65 \%$ (95\% confidence interval $46.4-77.7)$. The overall utility of this vaccine will require additional longer term analysis but these results are highly significant for the long term goal of immunizing against childhood infection of $H$. pylori. The study employed a number of strategies that distinguish it from previous $H$. pylori clinical vaccine trials, although it is difficult to identify which of these factors or combination of factors is primarily responsible for achieving such improved efficacy over previous trials.

First, the study involved children aged 6-15 y old, a departure from all previous clinical trials which were performed exclusively in adults. In this light, it is worth considering whether vaccination might have been even more efficacious if delivered within the first several years of life on a schedule consistent with most childhood vaccines. Epidemiologic data show that in many societies $H$. pylori infection occurs within the first $5 \mathrm{y}$ of life and often before the age of $2 \mathrm{y}$ (55). However to the extent infection can continue to occur throughout the life, a vaccine would optimally be useful when applied to teenagers and adults as well. Additionally, should this vaccine possess therapeutic potential it would increase effectiveness in that the infected pool of hosts within a given population could be reduced, thereby limiting opportunity for spread. More information will be needed to determine if the age of application is important for vaccine efficacy and to determine the utility of vaccination at differing stages of life.

Second, the vaccine was given as a prophylactic. While two of the four previous clinical trials were also prophylactic vaccines, each of those trials relied upon an experimental challenge with well characterized strains of $H$. pylori $(52,53,56)$. Zeng et al. tested the efficacy of their vaccine against naturally acquired $H$. pylori infection. It is likely the bacterial loads encountered naturally are lower than what investigators have used experimentally. Third, the scale of this most recent study was over two orders of magnitude higher than the average of the previous four studies. More than 5,700 participants were assessed for eligibility with 2,232 eligible subjects each eventually assigned to vaccine and placebo groups. Participants successfully completing the three dose vaccination schedule included 2,199 receiving vaccine and 2,204 receiving the placebo.

The nature of the vaccine was a combination of tested and new technology with regard to clinical trials for $H$. pylori immunizations. The vaccine was administered orally on days 0,14 , and 28 . The antigen consisted of a fusion protein generated from a recombinant gene encoding the $H$. pylori urease B subunit and the exotoxin B subunit of E. coli heat labile protein. The investigators therefore selected an antigen widely used in both animal and clinical trials fused to a mucosal adjuvant subunit. Many H. pylori protein antigens have been tested for vaccine efficacy in animal models including those attributable to pathogenesis including urease, CagA, VacA, catalase, and others (43). No single protein has been identified to be superior to the others. There may be some benefit to using a multivalent vaccine as demonstrated in mice (57), and the inclusion of additional proteins may improve the efficacy of the vaccine tested in China. Never the less, the selection of urease is supported by previous studies. In many respects the strategy employed by Zeng et al. is remarkably similar to that originally described by Czinn and Nedrud $(38,41)$. It consisted of an oral vaccine administered several times over the course of $28 \mathrm{~d}$ and included a protein antigen combined with a bacterial exotoxin mucosal adjuvant. The nature of their mucosal adjuvant construct however makes their results all the more surprising.

As discussed above, bacterial exotoxins derive their mucosal adjuvanticity from the enzymatic activity of the A subunit. Unfortunately, the A subunit is also responsible for the toxicity associated with the exotoxin. Preparations of B subunit devoid of any contaminating A subunit are safe but lack adjuvanticity (58-61). It is for this reason that efforts have been made to construct a holotoxin with point mutations in the $\mathrm{A}$ subunit in an attempt to retain adjuvanticity while minimizing the toxic effects of the enterotoxin. The function of the $\mathrm{B}$ subunit is to bind to the epithelium. In the context of the construct employed by Zeng et al. therefore, the fusion protein would potentially bind to the gastrointestinal epithelium but would lack adjuvancity. This strategy has been tested in many experimental models to induce immunity but has also been used to induce immunologic tolerance to the fusion protein to treat autoimmune diseases in animal models (62-67). Zeng et al. demonstrated significant increases in urease B-specific serum IgG and salivary IgA titers by 1 mo postimmunization. By 36 mo serum IgG titers decreased but remained fourfold higher for immunized subjects compared with those receiving placebo. Although antibodies have not been determined to be required for protection against $H$. pylori $(68,69)$ and are not correlated with immunity to $H$. pylori, increases in antigen specific antibodies can be used as a measure of vaccine immunogenicity. In the absence of a third group of subjects receiving 


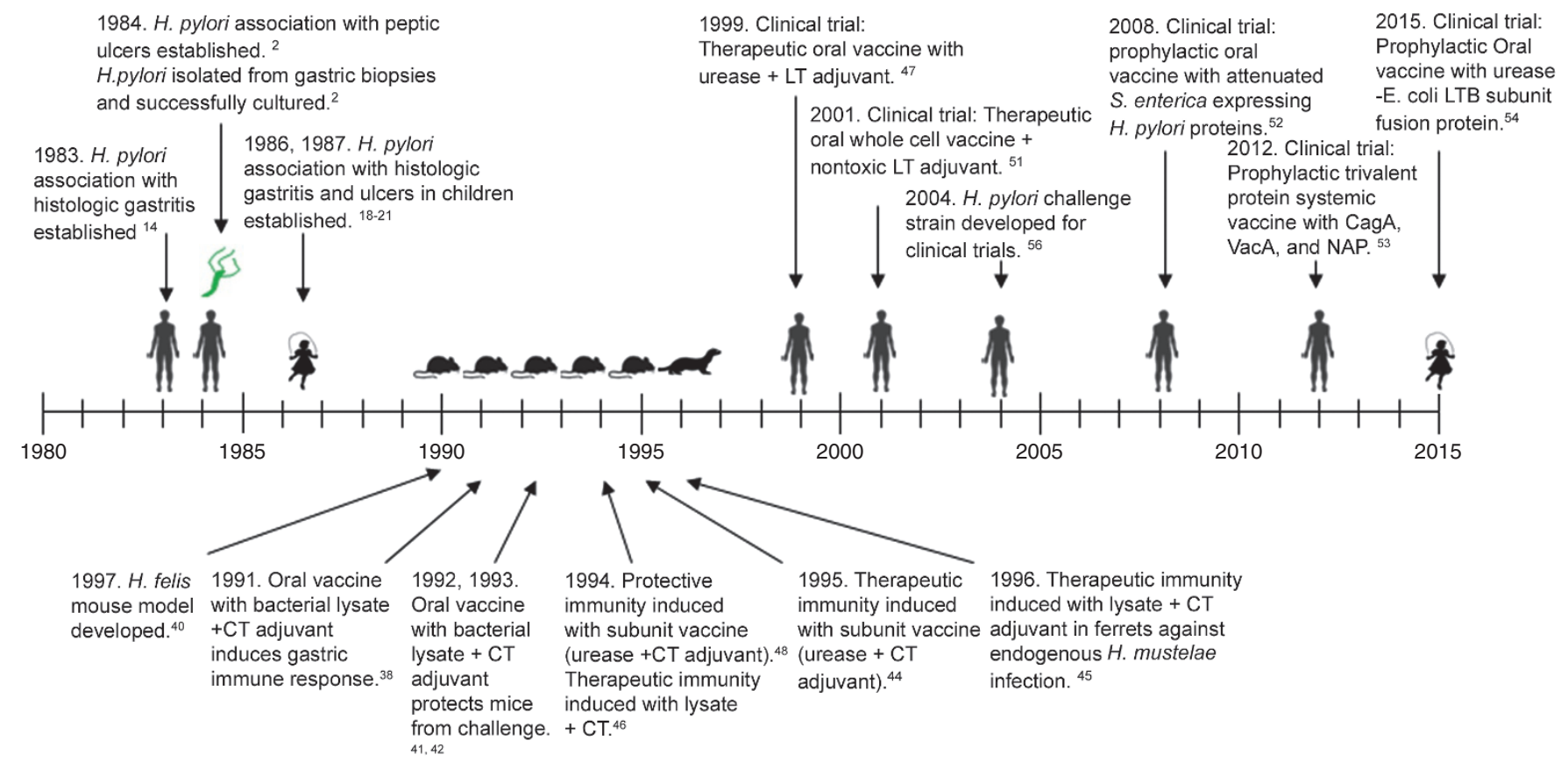

Figure 1. Milestones in the advancement of treating and preventing H. pylori associated diseases through vaccination.

urease B without adjuvant however, it is impossible to determine whether the antibody titers and protection achieved was due to the presence of the fused enterotoxin $B$ subunit or would have been achieved by $15 \mathrm{mg}$ doses of urease B protein alone.

It is also worth noting that the vaccine construct used by Zeng et al. was demonstrated to be safe for the participants. Although $7 \%$ of subjects receiving the vaccine experienced adverse reactions within the first few days of immunization, the numbers were equivalent for subjects receiving the placebo. The most common reaction observed was vomiting followed by fever and headache but in all cases conditions resolved within 24 hours. Subjects receiving the vaccine did experience bloating more than the placebo control group $(P=$ 0.0427 ) but this condition was also mild and quickly resolved. All subjects were fasted for at least $2 \mathrm{~h}$ and then given a buffer solution consisting of sodium bicarbonate and sodium citrate prior to receiving $80 \mathrm{ml}$ of vaccine or placebo.

Gastric health for pediatric as well as adult patients has benefitted greatly as a result of Warren and Marshall's identification of $H$. pylori and it's etiology with gastritis and peptic ulcer disease in the mid 1980's. Those previously diagnosed with a gastric or duodenal ulcer faced a lifetime of pain and suffering, a series of bromides of questionable efficacy, and a bland diet, to say nothing of surgical remedies. Today a diagnosis of peptic ulcer disease accompanied by $H$. pylori infection can be permanently cured in most cases with antimicrobial therapy. Although the etiology of symptomatic gastritis is multifaceted and complex, it is clear that when $H$. pylori infection is present, eradication of H. pylori often cures the disease. The development of a vaccine to protect against $H$. pylori has been slow to develop (Figure 1). Until recently, clinical trials offered little encouragement. The most recent large scale trial however is promising. A vaccine that demonstrates $65 \%$ efficacy after 3 y may require improvement, but there is no doubt their ureaseB-E. coli labile toxin B subunit fusion protein is capable of inducing protective immunity in the absence of untoward side effects. The study readily suggests a trend for continued research and trials including the inclusion of additional antigens fused to LTB, the testing of vaccination at earlier ages, and the testing of the vaccine when applied therapeutically to infected hosts. It will also be important to determine longevity of protection and the efficacy of vaccination when comparing populations at varying risks for reinfection. Future studies aimed at the improvement of this vaccine candidate, or which build upon its success may ultimately lead to an effective strategy for eliminating $H$. pylori from large population centers where $H$. pylori is endemic and H. pylori-associated diseases are prevalent.

\section{STATEMENT OF FINANCIAL SUPPORT}

No financial support from extramural sources was received in support of this work.

Disclosure: The authors have no disclosures.

\section{REFERENCES}

1. Eurogast Study Group. An international association between Helicobacter pylori infection and gastric cancer. Lancet 1993;341:1359-62.

2. Marshall BJ, Warren JR. Unidentified curved bacilli in the stomach of patients with gastritis and peptic ulceration. Lancet 1984;1:1311-5.

3. NIH Consensus Conference. Helicobacter pylori in peptic ulcer disease. J Am Med Assoc 1994;272:65-69.

4. Parsonnet J, Friedman GD, Vandersteen DP, et al. Helicobacter pylori infection and the risk of gastric carcinoma. N Engl J Med 1991;325: $1127-31$.

5. World Health Organization. Infection with Helicobacter pylori. Schistosomes, Liver Flukes and Helicobacter pylori. Lyon: International Agency for Research on Cancer, 1994; 177-241.

6. Graham DY, Malaty HM, Evans DG, Evans DJ Jr, Klein PD, Adam E. Epidemiology of Helicobacter pylori in an asymptomatic population in the United States. Effect of age, race, and socioeconomic status. Gastroenterol 1991;100:1495-501. 
7. World Gastroenterology Organization. Global Guidelines: Helicobacter pylori in developing countries, 2010. (http://www.worldgastroenterology. org/UserFiles/file/guidelines/helicobacter-pylori-english-2010.pdf.).

8. Yamaoka Y, Kato M, Asaka M. Geographic differences in gastric cancer incidence can be explained by differences between Helicobacter pylori strains. Intern Med 2008;47:1077-83.

9. Doenges LS. Spirochetes in the gastric glands of Macacus rhesus and of man without related disease. Arch Pathol 1939;27:469-77.

10. Freedberg AS, Barron LE. The presence of spirochetes in human gastric mucosa. Am J Dig Dis 1940;7:443-45.

11. Krienitz W. Ueber das auftreten von mageninhalt bei carcinoma ventriculi. Dtsch Med Wochenschr 1906;32:872.

12. Steer HW, Colin-Jones DG. Mucosal changes in gastric ulceration and their response to carbenoxolone sodium. Gut 1975;16:590-7.

13. Palmer ED. Investigation of the gastric mucosa spirochetes of the human. Gastroenterol 1954;27:218-20.

14. Warren JR. Unidentified curved bacilli on gastric epithelium in active chronic gastritis. The Lancet 1983;I:1273-75.

15. Marshall BJ, Armstrong JA, McGechie DB, Glancy RJ. Attempt to fulfil Koch's postulates for pyloric Campylobacter. Med J Aust 1985;142:436-9.

16. Morris A, Nicholson G. Ingestion of Campylobacter pyloridis causes gastritis and raised fasting gastric $\mathrm{pH}$. Am J Gastroenterol 1987;82:192-9.

17. Ruhl CE, Sayer B, Byrd-Holt DD, Brown DM. Costs of digestive diseases. In: Everhart JE, ed. The Burden of Digestive Diseases in the United States. US Department of Health and Human Services, Public Health Service, national Institutes of Health, National Institute of Diabetes and Digestive and Kidney Diseases. Washington, D.C.: US Government Printing Office, 2008:37-147.

18. Cadranel S, Goossens H, De Boeck M, Malengreau A, Rodesch P, Butzler JP. Campylobacter pyloridis in children. Lancet 1986;1:735-6.

19. Czinn SJ, Dahms BB, Jacobs GH, Kaplan B, Rothstein FC. Campylobacterlike organisms in association with symptomatic gastritis in children. J Pediatr 1986;109:80-3.

20. Hill R, Pearman J, Worthy P, Caruso V, Goodwin S, Blincow E. Campylobacter pyloridis and gastritis in children. Lancet 1986;1:387.

21. Drumm B, Sherman P, Cutz E, Karmali M. Association of Campylobacter pylori on the gastric mucosa with antral gastritis in children. N Engl J Med 1987;316:1557-61.

22. Fallone CA, Chiba N, van Zanten SV, et al. The Toronto consensus for the treatment of Helicobacter pylori infection in adults. Gastroenterol 2016;151:51-69.e14.

23. Fischbach LA, Nordenstedt H, Kramer JR, et al. The association between Barrett's esophagus and Helicobacter pylori infection: a meta-analysis. Helicobacter 2012;17:163-75.

24. Rokkas T, Pistiolas D, Sechopoulos P, Robotis I, Margantinis G. Relationship between Helicobacter pylori infection and esophageal neoplasia: a meta-analysis. Clin Gastroenterol Hepatol 2007;5:1413-7, 1417.e1-2.

25. Rubenstein JH, Inadomi JM, Scheiman J, et al. Association between Helicobacter pylori and Barrett's esophagus, erosive esophagitis, and gastroesophageal reflux symptoms. Clin Gastroenterol Hepatol 2014;12:239-45.

26. Sonnenberg A, Lash RH, Genta RM. A national study of Helicobactor pylori infection in gastric biopsy specimens. Gastroenterol 2010;139: 1894-1901.e2; quiz e12.

27. Dellon ES, Peery AF, Shaheen NJ, et al. Inverse association of esophageal eosinophilia with Helicobacter pylori based on analysis of a US pathology database. Gastroenterol 2011;141:1586-92.

28. Luther J, Dave M, Higgins PD, Kao JY. Association between Helicobacter pylori infection and inflammatory bowel disease: a meta-analysis and systematic review of the literature. Inflamm Bowel Dis 2010;16:1077-84.

29. Chen Y, Blaser MJ. Inverse associations of Helicobacter pylori with asthma and allergy. Arch Intern Med 2007;167:821-7.

30. Chen Y, Blaser MJ. Helicobacter pylori colonization is inversely associated with childhood asthma. J Infect Dis 2008;198:553-60.

31. Reibman J, Marmor M, Filner J, et al. Asthma is inversely associated with Helicobacter pylori status in an urban population. PLoS One 2008;3: e4060.
32. Arnold IC, Dehzad N, Reuter S, et al. Helicobacter pylori infection prevents allergic asthma in mouse models through the induction of regulatory T cells. J Clin Invest 2011;121:3088-93.

33. Oertli M, Sundquist M, Hitzler I, et al. DC-derived IL-18 drives Treg differentiation, murine Helicobacter pylori-specific immune tolerance, and asthma protection. J Clin Invest 2012;122:1082-96.

34. Spangler BD. Structure and function of cholera toxin and the related Escherichia coli heat-labile enterotoxin. Microbiol Rev 1992;56:622-47.

35. Elson CO, Ealding W. Generalized systemic and mucosal immunity in mice after mucosal stimulation with cholera toxin. J Immunol 1984;132: 2736-41.

36. Lycke N, Holmgren J. Strong adjuvant properties of cholera toxin on gut mucosal immune responses to orally presented antigens. Immunology 1986;59:301-8.

37. Nedrud JG, Liang XP, Hague N, Lamm ME. Combined oral/nasal immunization protects mice from Sendai virus infection. J Immunol 1987;139:3484-92.

38. Czinn SJ, Nedrud JG. Oral immunization against Helicobacter pylori. Infect Immun 1991;59:2359-63.

39. Fox JG, Correa P, Taylor NS, et al. Helicobacter mustelae-associated gastritis in ferrets. An animal model of Helicobacter pylori gastritis in humans. Gastroenterol 1990;99:352-61.

40. Lee A, Fox JG, Otto G, Murphy J. A small animal model of human Helicobacter pylori active chronic gastritis. Gastroenterol 1990;99:1315-23.

41. Czinn SJ, Cai A, Nedrud JG. Protection of germ-free mice from infection by Helicobacter felis after active oral or passive IgA immunization. Vaccine 1993;11:637-42.

42. Chen M, Lee A, Hazell S. Immunisation against gastric helicobacter infection in a mouse/Helicobacter felis model. Lancet 1992;339:1120-1.

43. Blanchard T, Nedrud J. Helicobacter pylori vaccines. In: Sutton P, Hazel M eds. Helicobacter Pylori in the 21st Century. Wallingford, UK: CABI, 2010:167-189.

44. Corthésy-Theulaz I, Porta N, Glauser M, et al. Oral immunization with Helicobacter pylori urease B subunit as a treatment against Helicobacter infection in mice. Gastroenterol 1995;109:115-21.

45. Cuenca R, Blanchard TG, Czinn SJ, et al. Therapeutic immunization against Helicobacter mustelae in naturally infected ferrets. Gastroenterol 1996;110:1770-5.

46. Doidge C, Crust I, Lee A, Buck F, Hazell S, Manne U. Therapeutic immunisation against Helicobacter infection. Lancet 1994;343:914-5.

47. Michetti P, Kreiss C, Kotloff KL, et al. Oral immunization with urease and Escherichia coli heat-labile enterotoxin is safe and immunogenic in Helicobacter pylori-infected adults. Gastroenterol 1999;116:804-12.

48. Michetti P, Corthésy-Theulaz I, Davin C, et al. Immunization of BALB/c mice against Helicobacter felis infection with Helicobacter pylori urease. Gastroenterol 1994;107:1002-11.

49. Banerjee S, Medina-Fatimi A, Nichols R, et al. Safety and efficacy of low dose Escherichia coli enterotoxin adjuvant for urease based oral immunisation against Helicobacter pylori in healthy volunteers. Gut 2002;51: 634-40.

50. Sougioultzis S, Lee CK, Alsahli M, et al. Safety and efficacy of E coli enterotoxin adjuvant for urease-based rectal immunization against Helicobacter pylori. Vaccine 2002;21:194-201.

51. Kotloff KL, Sztein MB, Wasserman SS, Losonsky GA, DiLorenzo SC, Walker RI. Safety and immunogenicity of oral inactivated whole-cell Helicobacter pylori vaccine with adjuvant among volunteers with or without subclinical infection. Infect Immun 2001;69:3581-90.

52. Aebischer T, Bumann D, Epple HJ, et al. Correlation of $\mathrm{T}$ cell response and bacterial clearance in human volunteers challenged with Helicobacter pylori revealed by randomised controlled vaccination with Ty21a-based Salmonella vaccines. Gut 2008;57:1065-72.

53. Malfertheiner P, Selgrad M, Wex T, et al. Efficacy of an investigational recombinant antigen based vaccine against a CagA $\mathrm{H}$. pylori infectious challenge in healthy volunteers. Gastroenterol 2012;142:S-184.

54. Zeng M, Mao XH, Li JX, et al. Efficacy, safety, and immunogenicity of an oral recombinant Helicobacter pylori vaccine in children in China: 
a randomised, double-blind, placebo-controlled, phase 3 trial. Lancet 2015;386:1457-64.

55. Feldman RA, Eccersley AJ, Hardie JM. Epidemiology of Helicobacter pylori: acquisition, transmission, population prevalence and disease-toinfection ratio. Br Med Bull 1998;54:39-53.

56. Graham DY, Opekun AR, Osato MS, et al. Challenge model for Helicobacter pylori infection in human volunteers. Gut 2004;53:1235-43.

57. Ferrero RL, Thiberge JM, Kansau I, Wuscher N, Huerre M, Labigne A. The GroES homolog of Helicobacter pylori confers protective immunity against mucosal infection in mice. Proc Natl Acad Sci USA 1995;92:6499-503.

58. Blanchard TG, Lycke N, Czinn SJ, Nedrud JG. Recombinant cholera toxin B subunit is not an effective mucosal adjuvant for oral immunization of mice against Helicobacter felis. Immunology 1998;94:22-7.

59. Lycke N, Karlsson U, Sjölander A, Magnusson KE. The adjuvant action of cholera toxin is associated with an increased intestinal permeability for luminal antigens. Scand J Immunol 1991;33:691-8.

60. Lycke N, Tsuji T, Holmgren J. The adjuvant effect of Vibrio cholerae and Escherichia coli heat-labile enterotoxins is linked to their ADPribosyltransferase activity. Eur J Immunol 1992;22:2277-81.

61. Vajdy M, Lycke NY. Cholera toxin adjuvant promotes long-term immunological memory in the gut mucosa to unrelated immunogens after oral immunization. Immunology 1992;75:488-92.

62. Arakawa T, Yu J, Chong DK, Hough J, Engen PC, Langridge WH. A plantbased cholera toxin B subunit-insulin fusion protein protects against the development of autoimmune diabetes. Nat Biotechnol 1998;16:934-8.
63. Bergerot I, Ploix C, Petersen J, et al. A cholera toxoid-insulin conjugate as an oral vaccine against spontaneous autoimmune diabetes. Proc Natl Acad Sci USA 1997;94:4610-4.

64. Petersen JS, Bregenholt S, Apostolopolous V, et al. Coupling of oral human or porcine insulin to the B subunit of cholera toxin (CTB) overcomes critical antigenic differences for prevention of type I diabetes. Clin Exp Immunol 2003;134:38-45.

65. Ploix C, Bergerot I, Durand A, Czerkinsky C, Holmgren J, Thivolet C. Oral administration of cholera toxin $\mathrm{B}$-insulin conjugates protects NOD mice from autoimmune diabetes by inducing CD4+ regulatory T-cells. Diabetes 1999;48:2150-6.

66. Sun JB, Holmgren J, Czerkinsky C. Cholera toxin B subunit: an efficient transmucosal carrier-delivery system for induction of peripheral immunological tolerance. Proc Natl Acad Sci USA 1994;91:10795-9.

67. Sun JB, Rask C, Olsson T, Holmgren J, Czerkinsky C. Treatment of experimental autoimmune encephalomyelitis by feeding myelin basic protein conjugated to cholera toxin B subunit. Proc Natl Acad Sci USA 1996;93:7196-201.

68. Blanchard TG, Czinn SJ, Redline RW, Sigmund N, Harriman G, Nedrud JG. Antibody-independent protective mucosal immunity to gastric helicobacter infection in mice. Cell Immunol 1999;191:74-80.

69. Ermak TH, Giannasca PJ, Nichols R, et al. Immunization of mice with urease vaccine affords protection against Helicobacter pylori infection in the absence of antibodies and is mediated by MHC class II-restricted responses. J Exp Med 1998;188:2277-88. 